\title{
Copepods use chemical trails to find sinking marine snow aggregates
}

\author{
Lombard, Fabien; Koski, Marja; Kiørboe, Thomas
}

Published in:

Limnology and Oceanography

Link to article, DOI:

10.4319/lo.2013.58.1.0185

Publication date:

2013

Link back to DTU Orbit

Citation (APA):

Lombard, F., Koski, M., \& Kiørboe, T. (2013). Copepods use chemical trails to find sinking marine snow aggregates. Limnology and Oceanography, 58(1), 185-192. https://doi.org/10.4319/lo.2013.58.1.0185

\section{General rights}

Copyright and moral rights for the publications made accessible in the public portal are retained by the authors and/or other copyright owners and it is a condition of accessing publications that users recognise and abide by the legal requirements associated with these rights.

- Users may download and print one copy of any publication from the public portal for the purpose of private study or research.

- You may not further distribute the material or use it for any profit-making activity or commercial gain

- You may freely distribute the URL identifying the publication in the public portal

If you believe that this document breaches copyright please contact us providing details, and we will remove access to the work immediately and investigate your claim. 
2

3 Lombard, F., ${ }^{\text {a,b,c, }}{ }^{*}$ M. Koski, ${ }^{\text {a }}$ and T. Kiørboe ${ }^{\mathrm{a}}$

$4 \quad{ }^{\mathrm{a}}$ Centre for Ocean Life, National Institute for Aquatic Resources, Section for Ocean

5 Ecology and Climate, Technical University of Denmark Charlottenlund, Denmark

6 baboratoire d'Océanographie Physique et Biogéochimique - Unité Mixte de Recherche

76535 (LOPB - UMR 6535) Campus de Luminy, Marseille, France.

$8{ }^{\mathrm{c}}$ Université Pierre et Marie Curie-Paris Paris 6, Unité Mixte de Recherche 7093, Laboratoire

9 d'Océanographie de Villefranche, Villefranche sur Mer, France

$10 *$ Corresponding author: lombard@obs-vlfr.fr

11 Running head: Copepods and marine snow chemical trails 
13 Funding was provided by a Marie Curie Intra-European Fellowship 221696 award and the 14 French program Agence Nationale de la Recherche ANR-10-PDOC-005-01 'Ecogely' to FL.

15 The Danish Council for Independent Research provided further support. We thank Martin 16 Lilley for English corrections on the manuscript and the two anonymous reviewers for their 17 improvements on the manuscript. 
Abstract

Copepods are major consumers of sinking marine particles and hence reduce the efficiency of the biological carbon pump. Their high abundance on marine snow suggests that they can detect sinking particles remotely. By means of laboratory observations we show that the copepod Temora longicornis can detect chemical trails originating from sinking marine snow particles (appendicularian houses). The chemical cue was detected by copepods from a distance of $>25$ particle radii, with the probability of detection decreasing with distance. The behavior of $T$. longicornis following the trail resembled the behavior of males tracking pheromone trails, although with a lower tracking velocity. Upon finding a house, the copepod would attach for a short period (10-30 s) and feed intensively. Due to short residence times, daily feeding rates were moderate. Our results demonstrate that even $T$. longicornis, a species usually considered a micro-particle feeder, is able to detect and feed on marine snow aggregates. If similar behaviors are displayed by the more dedicated aggregate-feeding copepods, a topic that remains unexplored, the effect of copepods on vertical flux attenuation may be significant. 


\section{INTRODUCTION}

Sinking particles are the main vehicles for the vertical transport of biogenic carbon from the sea surface to the ocean interior and the seafloor (Fowler and Knauer 1986). The downward flux of particles, however, attenuates near exponentially with depth due to the degradation of the particulate material as it sinks (Martin et al. 1987). Bacteria and zooplankton are believed to be approximately equally important for the remineralization of sinking particles (Steinberg et al. 2008). Bacteria rapidly colonize sinking particles, facilitated by their chemotactic behavior (Stocker et al. 2008), and account for a surprisingly constant carbon-specific degradation rate of ca. $0.1 \mathrm{~d}^{-1}$ (Ploug and Grossart 2000). This quantitative understanding of the role of bacteria can readily be incorporated in models of flux attenuation (Buesseler and Boyd 2009). The contribution of zooplankton to flux attenuation is much more variable and the underlying processes are poorly known (Steinberg et al. 2008). The lack of knowledge of zooplankton processes has been cited as one of the main factors hampering the advances in modeling biogeochemical fluxes (Boyd and Trull 2007).

Zooplankton may occur in high abundances on marine snow aggregates in the upper ocean (Steinberg et al. 1994; Kiørboe 2000), and their grazing on aggregate constituents may be substantial (Koski et al. 2005). Likewise, large sinking particles may be a significant food source for many zooplankters (Dagg 1993). It is unclear, however, how the zooplankters find these particles. Random encounter is an insufficient process to explain observed abundance of zooplankton on aggregates and remote detection has been invoked to account for the high densities of zooplankton on snow particles (Kiørboe 2000; Kiørboe and Thygesen 2001; Jackson and Kiørboe 2004). Bacterial activity on the surface of sinking particles may cause a substantial leakage of dissolved organic material (Smith et al. 1992), and sinking particles therefore leave an organic solute trail in their wake (Kiørboe 2001). It has been hypothesized 
that cruising zooplankters may encounter such trails, which, in turn, may lead the zooplankter to large, nutritious particles (Kiørboe and Thygesen 2001). Such behavior has been demonstrated in shrimps (Acetes sibogae) that follow scent trails left by sinking food particles (Hamner and Hamner 1977). Copepods are also known to be able to follow chemical trails. This has been demonstrated for copepod males in particular that follow pheromone trails left by receptive females (Doall et al. 1998), but copepodites and females may also be able to follow artificial trails of amino acids (Kiørboe 2001) or dextrane (Yen et al. 2004).

We here test the hypothesis that copepods may find and follow chemical trails left by sinking marine snow particles. We use discarded appendicularian houses as a source of particles, as it has been demonstrated that the sinking house leaves a trail in its wake (visualized in Lombard and Kiørboe 2010, their fig. 3). Discarded houses are an abundant type of marine snow (Alldredge and Gotschalk 1990) and they may contribute significantly to carbon export from the surface ocean (Robison et al. 2005). Appendicularian houses are loaded with, for instance, algae, bacteria and ciliates that are concentrated on houses up to 2-4 orders of magnitude relative to the ambient water (Hansen et al 1996; Lombard et al 2010). The houses are thus concentrated packages of food, likely to be of a high nutritional value (similar to its attached particles). Here, we demonstrate that even a typical suspension feeding copepod (Temora longicornis) can feed on sinking marine snow, and that it finds the particles by following the scent trail that marine snow leave in their wake.

\section{METHODS}

\section{Origin and culture of animals}

Experiments were conducted using both cultivated and freshly collected copepods and appendicularians ('culture' and 'wild' conditions). Cultured appendicularians (Oikopleura dioica) and copepods (Temora longicornis), originally collected in the Øresund $\left(56^{\circ} 03^{\prime} \mathrm{N}\right.$; 
$\left.12^{\circ} 39^{\prime} \mathrm{E}\right)$, western Baltic Sea, were grown in the laboratory $\left(18^{\circ} \mathrm{C}\right.$; salinity 35$)$ for $>10$ generations following standard protocols (Lombard and Kiørboe 2010). The appendicularians were fed a mixture of diatoms (Thalassosira pseudonana) and phytoflagellates (Isochrysis galbana and Rhodomonas salina). Under these conditions $O$. dioica produces 7-8 houses $\mathrm{d}^{-1}$ (Fenaux 1985). Temora longicornis was fed a mixture of $R$. salina, Thalassiosira weissflogii and dinoflagellates (Prorocentrum minimum and Heterocapsa sp.) in excess, which allowed for relatively high ingestion and egg production rates.

Wild copepods and appendicularians were collected from a pier in the Øresund $\left(55^{\circ} 45^{\prime} \mathrm{N}\right.$; $12^{\circ} 35.5^{\prime}$ E) $24 \mathrm{~h}$ prior to the experiment. Animals were collected with a bucket, which ensured their good condition. Wild animals were only used for behavioral observations. Salinity at the time of collection was 17 .

All experiments were conducted at $18^{\circ} \mathrm{C}$.

\section{Behavioral observations}

We recorded the behavior of Temora longicornis in the presence of sinking houses with a black and white Charge-Coupled Device camera (Watex, WAT-535EX, $25 \mathrm{~Hz}$ frame rate) equipped with a $35 \mathrm{~mm}$ lens to yield a field of view of ca. $5 \times 4 \mathrm{~cm}$. The experimental arena consisted of a $500 \mathrm{~mL}$ transparent plexiglas chamber (dimensions $5 \times 5 \times 20 \mathrm{~cm}$ ). The chamber was placed in a dark room and illuminated with collimated infrared light from a light-emitting diode that was shined through the chamber towards the camera. This way shadow images of copepods and sinking houses were obtained. Both the camera and the light were mounted on a motorized support which allowed moving the whole system in two dimensions. Individual particles could thus be followed as they were sinking through the water column without modifying the settings (size calibration) of the camera. 
For behavioral observations we used either newly discarded houses (5-10 min), or houses that had aged for 1-2 $\mathrm{h}$. Fresh and aged houses differ in their properties, because houses deflate rapidly once discarded. Thus, fresh houses leak internal water and food particles (Lombard and Kiørboe 2010). Prior to an experiment, the chamber was filled with filtered water from the appendicularian culture (or freshly collected sea water for wild conditions). 100-200 copepods were then added and allowed $24 \mathrm{~h}$ to acclimate. The high density of copepods was chosen to increase the number of encounter events during the video recordings and was assumed not to affect the swimming behavior (Dur et al. 2011).

Observations were made by gently introducing appendicularian houses (one at a time, up to 15 times) in the surface of the chamber, and then following the sinking house and nearby copepods with the camera until the house reached the bottom of the chamber ( $\sim 5 \mathrm{~min})$. Video sequences were later analyzed using a MatLab script that follows frame by frame the position of targeted objects. The following parameters were retrieved: sizes, sinking trajectories, and speeds of appendicularian houses; swimming trajectories and speeds of copepods that reacted to a house (before and after encountering the chemical plume of the house); and copepod residence time on the houses. A total of 232 copepod reactions were recorded and analyzed.

\section{Feeding experiment}

We estimated the feeding of copepods on discarded appendicularian houses by an indirect approach, by quantifying the number of fecal pellets that copepods produce when offered houses. Although dependent on food type, pellet production can be considered to be linearly related to feeding rate (Besiktepe and Dam 2002). Ten adult T. longicornis were incubated for $48 \mathrm{~h}$ in $600 \mathrm{~mL}$ screw-cap bottles in $0.2-\mu \mathrm{m}$ filtered sea water, containing a variable number of aged 2-3 mm diameter houses $(0 ; 5 ; 10 ; 20 ; 30 ; 40 ; 50$ houses per bottle). The highest tested densities of houses are in the upper end of that observed in nature, representing bloom 
conditions, where densities of appendicularians (each producing 13-26 houses $\mathrm{d}^{-1}$; Sato et al. 2003) may exceed 50, $000 \mathrm{~m}^{-3}$ (Uye and Ishino 1995). All incubations were done in triplicates. The bottles were mounted on a slowly rotating wheel (1 round per minute) and incubated in darkness. Water and houses were changed after $24 \mathrm{~h}$ and the pellets were counted at 24 and $48 \mathrm{~h}$. For each counting, the content of the bottles was gently filtered onto a submerged $10 \mu \mathrm{m}$ filter and the copepods were immediately transferred to the new water. Pellet production was used to qualitatively verify feeding on houses. Pellet production was also converted to a crude quantitative estimate of feeding rate, by assuming a pellet volume of $3.7510^{5} \mu \mathrm{m}^{3}$ (Dutz et al. 2008), a carbon content of $0.052 \mathrm{pg} \mu \mathrm{m}^{-3}$ (González and Smetacek 1994), and a carbon assimilation efficiency of 0.75 (Besiktepe and Dam 20020). The obtained feeding rates should be taken as conservative, since pellets volume and in particular carbon content are strongly dependent on copepod diet and could be substantially higher than the values used here (e.g. Ploug et al. 2008). Carbon content of female copepods from our culture was $7.5 \mu \mathrm{g} \mathrm{C}$ individual (ind.) $)^{-1}$ (Dutz et al. 2008).

\section{RESULTS}

\section{Behavioral observations}

We observed two different reactions of copepods to sinking houses (see also video A1 in the Web Appendix www.aslo.org/lo/toc/vol_xx/issue_x/xxxxa.xxx: 1) Direct encounter of a sinking house by a cruising copepod and subsequent attachment of the copepod to the house (as shown in video A1). This reaction was observed 86 times. 2) Remote detection and response to the house: When passing directly above the house the copepod abruptly changes its swimming direction and accelerates downward towards the house, following the presumed scent trail (as shown in video A1 and A2). The position where this happens is considered the detection point. While following the trail, the copepod doubles its swimming speed to $6-8 \mathrm{~mm}$ 
$157 \mathrm{~s}^{-1}$ (Table 1, Fig. 1) and swims in a zigzag course towards the particle. Of the 146 cases of

158 remote detection, the copepods were successful in actually finding and attaching to the 159 particle in only half of these (72).

160 The positions of detection points (Fig. 1) describe the extension of the chemical trail within 161 which the concentration of attractant exceeds the threshold for detection and response. The 162 length of the trail is about $35 \mathrm{~mm}$, corresponding to more than 25 particle radii, its maximum width about $4 \mathrm{~mm}$, and it is tapered toward its distal part. If the copepod detects the chemical signal with sensors at the tip of the antennules, then the 'real' width of the plume is $2 \mathrm{x}$ antennules length $(\sim 2 \times 0.6 \mathrm{~mm})$ less that suggested by the detection points, i.e., $2-3 \mathrm{~mm}$. The width of the plume can alternatively be estimated from the amplitude of the zigzag behavior ( $\sim 0.7 \mathrm{~mm}$; Table 1) plus $2 \mathrm{x}$ antennules length; again ca. $2 \mathrm{~mm}$.

The probability of detection declines hyperbolically with the distance to the particle (Fig. 2). There was no difference in average detection distance between fresh and aged houses, whereas there was a difference between the reactions in wild vs. culture conditions. Houses from wild appendicularians, were detected at a shorter distance by wild copepods than cultured copepods detected cultured houses (Table 1).

Copepods that managed to find a house attached to it and fed intensely from its surface as evidenced by constant activity of the feeding appendages. Sometimes the copepod would grab the house with its mandibles and apparently attempt to remove part of the house as evidenced by vigorous kicking of the swimming legs (see the Web Appendix). The copepods resided on the house for a relatively short $(<1 \mathrm{~min})$ but intense period, which was more than twice as long for wild than for cultured conditions (Table 1).

\section{Grazing and fecal pellets production}


This feeding activity resulted in the production of fecal pellets, and the production of pellets increased with the concentration of houses. Fitting a Holling Type II response to the observations yields a saturated pellet production rate of $34 \pm 13$ pellets ind. ${ }^{-1} \mathrm{~d}^{-1}$ (Fig. 3). This rate was however not reached, even at the highest concentration of houses $\left(83 \mathrm{~L}^{-1}\right)$. The maximum observed pellet production, ca. 15 pellets ind. ${ }^{-1} \mathrm{~d}^{-1}$, corresponds to an ingestion of $\sim 0.45 \mu \mathrm{g} \mathrm{C}$ ind..$^{-1} \mathrm{~d}^{-1}\left(6 \%\right.$ body weight $\left.\mathrm{d}^{-1}\right)$. The saturated consumption rate of appendicularian houses would then be about $0.9 \mu \mathrm{g} \mathrm{C}$ ind..$^{-1} \mathrm{~d}^{-1}\left(12 \%\right.$ body weight $\left.\mathrm{d}^{-1}\right)$, a sufficiently high rate to support copepod metabolism, while not allowing for a high growth or reproduction rate (Hernandez-León and Ikeda 2005). Thus even in saturating concentration of houses those only partly fulfill this copepod needs.

\section{DISCUSSION}

\section{Chemical or hydromechanical cues?}

Our results demonstrate that the copepod Temora longicornis is able to remotely detect sinking appendicularian houses, to subsequently follow the sinking track to the particle, and eventually to grab the particle and feed on it. To our knowledge, our results constitute the first demonstration of such particle tracking behavior in a copepod using realistic particles produced both under laboratory and wild conditions. Similar observations have previously been reported for planktonic shrimps tracking sinking detritus (Hamner and Hamner 1977), while the general assumption of the ability of copepods to follow chemical particle trails has until present been mainly based on theoretical considerations (Jackson and Kiørboe 2004).

The detection distance to a sinking $0.25 \mathrm{~cm}$ radius house was up to $3.5 \mathrm{~cm}$ at a position that was left by the particle over 25 seconds earlier. This strongly suggests that the cue utilized by the copepod is chemical rather than fluid mechanical. All our observations correspond to Reynolds numbers (Re) between 1 to 6 . Fluid disturbances at low Re dissipate rapidly due to 
viscosity; thus, the viscous time scale $\left(L^{2} / \eta\right.$, where $L$ is the linear dimension of the disturbance and $\eta$ the kinematic viscosity of the water) for a fluid signal of a spatial extension similar to the size of the sinking particles is $\sim 6 \mathrm{~s}$. The fluid disturbance also attenuates spatially, and the signal generated by the sinking particle at a distance of $3.5 \mathrm{~cm}$ can be estimated assuming Stokes flow for a translating sphere. Using the model developed by (Visser 2001), and assuming that the fluid velocity signal has to be $\geq 100 \mu \mathrm{m} \mathrm{s}^{-1}$ to be detected (Kiørboe 2011), the hydromechanical detection distance can be estimated as $0.4 \mathrm{~cm}$; if a 10x smaller detection signal is sufficient, this estimate increases to $1.2 \mathrm{~cm}$.

The behavior of the tracking copepods is consistent with them following a chemical trail. It resembles the behavior described for males tracking pheromone trails deposited by swimming females, although tracking velocities observed here $\left(<10 \mathrm{~mm} \mathrm{~s}^{-1}\right.$; Fig. 1, Table 1) are substantially lower than the swimming speed of female-tracking males of the same species (15-40 $\mathrm{mm} \mathrm{s}^{-1}$; Doall et al. 1998) and thus cannot be confused. The constant zigzagging along the invisible trail has been termed 'casting behavior' (Weissburg et al. 1998). It serves the purpose of constantly checking the radial extension of the trail, and is a prerequisite for being able to follow the trail. The tracking behavior of the copepods and the weakness of fluid mechanical disturbances generated by the sinking particles lead us to conclude that the cue used by the copepod to detect the sinking particle is chemical.

The spatial extension of the chemical plume, as evidenced by the distribution of detection points, is only partly consistent with that predicted from a model that describes the flow and concentration fields around a sinking sphere that leaks solutes (Kiørboe et al. 2001; see also Fig. 1A). The predicted solute distribution depends mainly on the Péclet number $(\mathrm{Pe}=a U / D$, where $a$ is the sphere radius, $U$ the sinking velocity, and $D$ the diffusivity of the leaking substance). The slower the particle sinks, and the higher the diffusivity of the leaked molecules, the broader the deposited trail. Assuming a diffusivity of $D=10^{-5} \mathrm{~cm}^{2} \mathrm{~s}^{-1}$, which is 
typical for small biological molecules, and the sinking velocities recorded for the discarded houses (Table 1), we get a Péclet number of about $10^{3}$, and a predicted solute distribution as shown in Fig. 1A. Obviously, the observed plume is much broader than that predicted, even when accounting for the length of the antennules of the copepods. The distribution rather resembles a situation for a Péclet number of order 100 or less (Fig. 1A). We argue that this is due to a much higher effective diffusivity of leaked substances in our experiments due to the mixing effect of both the swimming copepods and of the unavoidable convection currents in the experimental chamber. Observations and theory become consistent with one another if we assume a 10-fold higher effective diffusivity due to our experimental setup.

\section{Efficiency of particle detection}

From our observations, $T$. longicornis has almost twice the chance of remotely detecting a sinking house rather than directly encountering it (146 vs. 86 observations). However, judged from the observed ratio of direct collision-encounters to particle encounters facilitated by remote detection of sinking particles ( 86 vs. 71 ), remote detection only has a rather modest effect on the efficiency by which copepods can find sinking particles. However, we argue that our experimental design leads to an underestimation of this efficiency due to the mixing effects of the swimming copepods and small convection currents, but also that we can roughly quantify the error and estimate the real efficiency from our observations.

We use the 'moving point source model' of Jackson and Kiørboe (2004) to evaluate our results. According to this model, the length $(L)$, maximum width $(d$; derived from Jackson and Kiørboe 2004), and cross-sectional are $\left(A_{0}\right)$ of the plume can be estimated as

$$
L=\frac{Q}{4 \pi D C^{*}}
$$




$$
A_{0}=\frac{0.24}{D v^{0.5}}\left(\frac{Q}{\pi C^{*}}\right)^{1.5}
$$

where $Q\left(\mathrm{~mol} \mathrm{~s}^{-1}\right)$ is the rate at which solutes leak from the particle, $C^{*}\left(\mathrm{~mol} \mathrm{~cm}^{-3}\right)$ the

threshold concentration for detection, and $v\left(\mathrm{~cm} \mathrm{~s}^{-1}\right)$ the sinking velocity of the particle.

Equation 2 allows us to estimate the effective diffusivity of the chemical substance from the observed length $(3.5 \mathrm{~cm})$ and width $(0.2 \mathrm{~cm})$ of the plume and sinking velocity of the particles $\left(0.05-0.15 \mathrm{~cm} \mathrm{~s}^{-1}\right)$. The effective diffusivity thus estimated is about $1-310^{-4} \mathrm{~cm}^{2} \mathrm{~s}^{-1}$, one order of magnitude larger than the molecular diffusivity of small biological molecules, as also proposed above.

Kiørboe and Thygesen (2001) and Jackson and Kiørboe (2004) compiled empirical evidence to suggest that if the substance to which copepods respond is amino acids, then $Q$ $\left(\mathrm{mol} \mathrm{s}{ }^{-1}\right) \approx 10^{-12} a^{1.5}$ and $C^{*} \approx 10^{-11} \mathrm{~mol} \mathrm{~cm}^{-3}$, where $a$ is the radius of the sinking particle $(0.15$ $\mathrm{cm})$. If we accept these estimates and assume an effective diffusivity of $1-310^{-4} \mathrm{~cm}^{2} \mathrm{~s}^{-1}$ then the model predicts a plume length in our experiments of $1.67-5 \mathrm{~cm}$, in the range of our observations $(<3.5 \mathrm{~cm})$. Thus, our experimental observations are internally consistent and moreover consistent with independent estimates of particle leakage rates and copepod chemical sensitivity.

The encounter cross section of the chemical plume can be estimated as

$$
A=A_{0}+2 S L
$$

where $S$ is the length of the antennules $(0.6 \mathrm{~mm})$. This may be compared to the encounter cross section of the sinking particle itself $\left(\pi(a+S)^{2}\right)$ and used to estimate the enhancement in potential encounter rate due to chemical signals which are comparable to observed enhancement of encounter irrespectively to copepods or houses concentrations. Using the 
numbers above and a diffusivity not affected by experimental mixing effect, the enhancement for $2.5 \mathrm{~mm}$ diameter sinking houses is about two orders of magnitude. This estimate does not take into account the decreasing detection probability with increasing distance to the particle

(Fig. 2), and it does not consider the effect of turbulent mixing (Visser and Jackson 2004).

One may argue that the starved copepods used in our experiments were particularly responsive to food signals. As food in the ocean tends to be patchily distributed (Mitchell and Fuhrman 1989) and as starvation tolerance of neritic copepods such as Temora longicornis is limited (Koski and Klein Breteler 2003), an increased ability of starved copepods to detect food signals would be a relevant trait. However, our study was not designed to investigate the effect of starvation on behavior, but simply to demonstrate that chemical plumes behind sinking particles may significantly increase the possibility for zooplankters to find these nutritious particles.

\section{Feeding on sinking particles}

Jackson and Kiørboe (2004) explored the potential for zooplankters to find and feed on large sinking particles using the above model and parameter values consistent with those estimated here. While copepods are generally thought of as microphageous that mainly feed on microscopic phytoplankton and protozoans, the analysis of Jackson and Kiørboe (2004) suggested that large sinking particles may also be an important source of nutrition. The importance of sinking particles in the nutrition of zooplankton has also been suggested based on the metabolic demands of the zooplankton communities in the mesopelagic zone (Steinberg et al. 2008) and analysis of their gut fatty acid and pigment compositions (Wilson and Steinberg 2010).

The residence times of the copepods on the houses are short, consistent with earlier laboratory observations (Alldredge 1972). Reported residence times vary from minutes for 
pelagic organisms (Shanks and Walters 1997) to hours for semi-benthic species (Koski et al. 2005). It has been suggested that the short residence times are the result of a trade-off between the good feeding conditions and the elevated predation risk when attached to an aggregate, and that a copepod should remain on the aggregate only long enough to fill its gut (Kiørboe and Thygesen 2001). From estimated house encounter rates (calculated from observed copepods swimming speed, and sizes of particles and chemical trail) and consumption for $T$. longicornis, one can estimate that each house encounter leads to the ingestion of 3-5 $10^{-4} \mu \mathrm{g}$ $\mathrm{C}$, and an ingestion rate during attachment of $0.1-0.2 \mu \mathrm{g} \mathrm{C} \mathrm{h}^{-1}$. This is a very high instantaneous ingestion rate, but it would still take a copepod about 7-15 min to fill its gut (assumed to be the equivalent of one fecal pellet).

Our observations show that $T$. longicornis feed on discarded houses but even saturated feeding rates are only $10 \%$ of those reported for grazing on phytoplankton (Besiktepe and Dam 2002). The feeding rates $\left(\sim 4 \times 10^{-4} \mu \mathrm{g} \mathrm{C}\right.$ encounter $\left.{ }^{-1}\right)$ extrapolated to natural concentrations of discarded appendicularian houses (e.g., max. $6 \mathrm{~L}^{-1}$ in the North Sea; Koski et al. 2007; encounter rate calculated with a normal case of effective diffusivity) would be low, around $0.5 \mu \mathrm{g} \mathrm{C}$ ind. $\mathrm{d}^{-1}$. However, appendicularian houses are only one example of sinking particles, and copepods may also feed on other types of marine snow, such as diatom flocks or fecal pellets. Further, the feeding rates observed in the laboratory may underestimate those in the field. As suggested by the difference between cultured and wild copepods in our experiments, the wild copepods are more efficiently feeding on appendicularian houses. This may be due to the immediate history of the animals, e.g., hunger level or age, body size, or the different behaviors of the cultured and wild copepods (Tiselius et al. 1995).

T. longicornis is probably not a typical aggregate feeder and other zooplankters have morphologies and behaviors that make them particularly adapted to feed on marine snow aggregates. Copepods that are typically found on marine snow aggregates are harpacticoids, 
such as Microsetella norvegica, and copepods of the genus Oncaea (Shanks and Walters 1997). These species are not able to feed efficiently on suspended food, but are dependent on aggregates for feeding (Koski et al. 2005), and behavioral observations suggest that they readily feed on appendicularian houses (Ohtsuka and Kubo 1991). M. norvegica and semibenthic harpacticoids can have feeding rates ranging from $40 \%$ to $200 \%$ body weight ${ }^{-1} \mathrm{~d}^{-1}$ on appendicularian houses and settled diatoms (Koski et al. 2005; Koski et al. 2007), thus being considerably more efficient in aggregate feeding than $T$. longicornis.

Published estimates of the effect of copepods on the attenuation of sinking flux suggest potentially high degradation rates both in and below the euphotic zone, mainly depending on the abundance of potential grazers (Kiørboe 2000; Koski et al. 2005; Steinberg et al. 2008). Calanoid copepods, like Temora longicornis, are not normally considered feeders on large, sinking particles, and the feeding rates found here were lower than typically observed for $T$. longicornis feeding on suspended food (e.g., diverse phytoplankton). However, the degradation of sinking aggregates due to zooplankton grazing may be intense if typical detritivorous zooplankton exhibit similar aggregate-finding behavior as that reported here for T. longicornis. As calculations based on the abundance of some copepod species (typically Microsetella norvegica and Oncaea spp.) on marine snow suggest that random encounter is not sufficient to explain their high concentrations on aggregates (Kiørboe 2000), this seems likely. An efficient mechanism to find and colonize particles, together with their at times high abundances (up to 100 ind. $\mathrm{L}^{-1}$; Uye et al. 2002), suggest a potentially high effect of particlecolonizing copepods on the attenuation of vertical flux.

We have here demonstrated a mechanism by which copepods may locate sinking marine snow aggregates. This mechanism may account for the high abundances of copepods observed on aggregates, and is consistent with copepods contributing significantly to the vertical attenuation of particle flux in the ocean. Our observation is one step further in 
352 understanding the controls of flux attenuation and suggests that remote detection of chemical

353 cues can enhance the encounter and degradation rates by orders of magnitude from what

354 would be predicted based on the particle sizes and concentrations alone. 
Alldredge, A. L., and C. C. Gotschalk. 1990. The relative contribution of marine snow of different origins to biological processes in coastal waters. Cont. Shelf Res. 10: 41-58.

Besiktepe, S., and H. G. Dam. 2002. Coupling of ingestion and defecation as a function of diet in the calanoid copepod Acartia tonsa. Mar. Ecol. Prog. Ser. 229: 151-164.

Boyd, P. W., and T. W. Trull. 2007. Understanding the export of biogenic particles in oceanic waters: Is there consensus? Prog. Oceanogr. 72: 276-312.

Buesseler, K. O., and P. W. Boyd. 2009. Shedding light on processes that control particle export and flux attenuation in the twilight zone of the open ocean. Limnol. Oceanogr. 54: $1210-1232$.

Dagg, M. 1993. Sinking particles as a possible source of nutrition for the large calanoid copepod Neocalanus cristatus in the Sub-Arctic Pacific-Ocean Deep-Sea Res. I 40: $1431-1445$.

Doall, M. H., S. P. Colin, J. R. Strickler, and J. Yen. 1998. Locating a mate in 3D: The case of Temora longicornis. Phil. Trans. R. Soc. B 353: 681-689.

Dur, G., S. Souissi, F. Schmitt, F.-G. Michalec, M.-S. Mahjoub, and J.-S. Hwang. 2011. Effect of animal density, volume, and the use of 2D/3D recording on behavioral studies of copepods. Hydrobiol. 666: 197-214.

Dutz, J., M. Koski, and S. H. Jonasdottir. 2008. Copepod reproduction is unaffected by diatom aldehydes or lipid composition. Limnol. Oceanogr. 53: 225-235.

Fenaux, R. 1985. Rhythm of secretion of Oikopleurid's houses. Bull. Mar. Sci. 37: 498-503.

Fowler, S. W., and G. A. Knauer. 1986. Role of large particles in the transport of elements and organic compounds through the ocean water column. Prog. Oceanogr. 16: 147194. 
Fransz, H. G., J. M. Colebrook, J. C. Gamble, and M. Krause. 1991. The zooplankton of the North Sea. Neth. J. Sea Res. 28: 1-52.

González, H. E., and V. Smetacek. 1994. The possible role of the cyclopoid copepod Oithona in retarding vertical flux of zooplankton faecal material. Mar. Ecol. Prog. Ser. 113: 233-246.

Hamner, P., and W. M. Hamner. 1977. Chemosensory tracking of scent trails by planktonic shrimp Acetes Sibogae Australis. Science 195: 886-888.

Hansen, J.L.S., T. Kiørboe, and A. L. Alldredge. 1996. Marine snow derived from abandoned larvacean houses: Sinking rates, particle content and mechanisms of aggregate formation. Mar. Ecol. Prog. Ser. 141: 205-215.

Hernandez-León, S., and T. Ikeda. 2005. A global assessment of mesozooplankton respiration in the ocean. J. Plankton Res. 27: 153-158.

Jackson, G. A., and T. Kiørboe. 2004. Zooplankton use of chemodetection to find and eat particles. Mar. Ecol. Prog. Ser. 269: 153-162.

Kiørboe, T. 2000. Colonization of marine snow aggregates by invertebrate zooplankton: Abundance, scaling, and possible role. Limnol. Oceanogr. 45: 479-484.

Kiørboe, T. 2001. Formation and fate of marine snow: Small-scale processes with large-scale implications. Sci. Mar. 65: 57-71.

Kiørboe, T. 2011. How zooplankton feed: Mechanisms, traits and trade-offs. Biol. Rev. 86: 311-339.

Kiørboe, T., H. Ploug, and U. H. Thygesen. 2001. Fluid motion and solute distribution around sinking aggregates. I. Small-scale fluxes and heterogeneity of nutrients in the pelagic environment. Mar. Ecol. Prog. Ser. 211: 1-13. 
Kiørboe, T., and U. H. Thygesen. 2001. Fluid motion and solute distribution around sinking aggregates. II. Implication for remote detection by colonizing zooplankters. Mar. Ecol. Prog. Ser. 211: 15-25.

Koski, M., and W. C. M. Klein Breteler. 2003. Influence of diet on copepod survival in the laboratory. Mar. Ecol. Prog. Ser. 264: 73-82.

Koski, M., T. Kiorboe, and K. Takahashi. 2005. Benthic life in the pelagic: Aggregate encounter and degradation rates by pelagic harpacticoid copepods. Limnol. Oceanogr. 50: $1254-1263$.

Koski, M., E. F. Moller, M. Maar, and A. W. Visser. 2007. The fate of discarded appendicularian houses: Degradation by the copepod, Microsetella norvegica, and other agents. J. Plankton Res. 29: 641-654.

Lombard, F., and T. Kiørboe. 2010. Marine snow originating from appendicularian houses: Age-dependent settling characteristics. Deep-Sea Res. I 57: 1304-1313.

Lombard, F., D. Eloire, A. Gobet, L. Stemmann, J. Dolan, and G. Gorsky. 2010. Experimental and modeling evidence of ciliates-appendicularians interactions. Limnol. Oceanogr. 55: 77-90.

Martin, J. H., G. A. Knauer, D. M. Karl, and W. W. Broenkow. 1987. VERTEX - Carbon cycling in the Northeast Pacific. Deep-Sea Res. A 34: 267-285.

Mitchell, J. G., and J. A. Fuhrman. 1989. Centimeter scale vertical heterogeneity in bacteria and chlorophyll $a$. Mar. Ecol. Prog. Ser. 54: 141-148.

Ohtsuka, S., and N. Kubo. 1991. Larvaceans and their houses as important food for some pelagic copepods. Bull. Plankton Soc. Japan Spec. Vol.: 535-551.

Ploug, H., and H. P. Grossart. 2000. Bacterial growth and grazing on diatom aggregates: Respiratory carbon turnover as a function of aggregate size and sinking velocity. Limnol. Oceanogr. 45: 1467-1475. 
Ploug, H., M. H. Iversen, M. Koski, and E. T. Buitenhuis. 2008. Production, oxygen respiration rates, and sinking velocity of copepod fecal pellets: Direct measurements of ballasting by opal and calcite. Limnol. Oceanogr. 53: 469-476.

Robison, B. H., K. R. Reisenbichler, and R. E. Sherlock. 2005. Giant larvacean houses: Rapid carbon transport to the deep sea floor. Science 308: 1609-1611.

Sato, R., Y. Tanaka, and T. Ishimaru. 2003. Species-specific house productivity of appendicularians. Mar. Ecol. Prog. Ser. 259: 163-172.

Shanks, A. L., and K. Walters. 1997. Holoplankton, meroplankton, and meiofauna associated with marine snow. Mar. Ecol. Prog. Ser. 156: 75-86.

Smith, D. C., M. Simon, A. L. Alldredge, and F. Azam. 1992. Intensive hydrolytic activity on marine aggregates and implications for rapid particle dissolution. Nature 359: 139142.

Steinberg, D. K., M. W. Silver, C. H. Pilskaln, S. L. Coale, and J. B. Paduan. 1994. Midwater zooplankton communities on pelagic detritus (giant larvacean houses) in Monterey Bay, California. Limnol. Oceanogr. 39: 1606-1620.

Steinberg, D. K., B. A. S. Van Mooy, K. O. Buesseler, P. W. Boyd, T. Kobari, and D. M. Karl. 2008. Bacterial vs. zooplankton control of sinking particle flux in the ocean's twilight zone. Limnol. Oceanogr. 53: 1327-1338.

Stocker, R., J. R. Seymour, A. Samadani, D. E. Hunt, and M. F. Polz. 2008. Rapid chemotactic response enables marine bacteria to exploit ephemeral microscale nutrient patches. Proc. Natl. Acad. Sci. USA 105: 4209-4214.

Tiselius, P., B. Hansen, P. Jonsson, T. Kiørboe, T. G. Nielsen, S. Piontkovski, and E. Saiz. 1995. Can we use laboratory reared copepods for experiments? A comparison of feeding behavior and reproduction between a field and a laboratory population of Acartia tonsa. ICES J. Mar. Sci. 52: 369-376. 
Uye, S., and S. Ichino, 1995. Seasonal variations in abundance, size composition, biomass and production rate of Oikopleura dioica (Fol) (Tunicata: Appendicularia) in a temperate eutrophic inlet. J. Exp. Mar. Biol. Ecol. 189: 1-11.

Uye, S., I. Aoto, and T. Onbé. 1992. Seasonal population dynamics and production of Microsetella norvegica, a widely distributed but little-studied marine planktonic harpacticoid copepod. J. Plankton res. 24: 143-153.

Visser, A. W. 2001. Hydromechanical signals in the plankton. Mar. Ecol. Prog. Ser. 222: 124.

Visser, A. W., and G. A. Jackson. 2004. Characteristics of the chemical plume behind a sinking particle in af turbulent water column. Mar. Ecol. Prog. Ser. 283: 55-71.

Weissburg, M. J., M. H. Doall, and J. Yen. 1998. Following the invisible trail: Kinematic analysis of mate-tracking in the copepod Temora longicornis. Phil. Trans. R. Soc. B 353: 701-712.

Wilson, S. E., and D. K. Steinberg. 2010. Autotrophic picoplankton in mesozooplankton guts: evidence of aggregate feeding in the mesopelagic zone and export of small phytoplankton. Mar. Ecol. Prog. Ser. 412: 11-27.

Yen, J., A. Prusak, M. Caun, M. H. Doall, J. Brown, and J. R. Strickler. 2004. Signaling during mating in the pelagic copepod, Temora longicornis, p. 149-159. In L. Seuront and P. Strutton [eds.], Scales in aquatic ecology: measurements, analysis, modelling. CRC Press. 


\section{Tables}

Table 1 : Summary of copepod reactions to sinking aggregates at the different experimental conditions: Total number of observations $(n)$, number of direct encounters, number of chemical tracking events (including copepods that lose the trail), mean house size and sinking speed, reaction distance of the copepods to the sinking house, mean zigzag amplitude, residence time, and swimming velocity before and after encountering the chemical trail $( \pm$ SD). Differences between new and old houses have been tested as no significantly different for all observations ( $t$-test, $p>0.05)$ except houses size $(t$-test, $\mathrm{df}=230, p<0.001)$.

Differences between 'wild' and 'cultured' conditions are significant with respect to detection distance $(t$-test, $\mathrm{df}=148, p<0.001)$, residence time $(t$-test, $\mathrm{df}=110, p=0.012)$ and swimming and tracking velocities $(t$-tests, $\mathrm{df}=109, p=0.048$ and $\mathrm{df}=108, p<0.001$, respectively).

\begin{tabular}{|c|c|c|c|c|c|c|c|c|c|c|}
\hline \multirow[b]{2}{*}{$\begin{array}{l}\text { Observation } \\
\text { conditions }\end{array}$} & \multirow[b]{2}{*}{$n$} & \multicolumn{2}{|c|}{ Encounter } & \multirow[b]{2}{*}{$\begin{array}{l}\text { House size } \\
\qquad(\mathrm{mm})\end{array}$} & \multirow[b]{2}{*}{$\begin{array}{l}\text { House sinking } \\
\text { speed }\left(\mathrm{m} \mathrm{d}^{-1}\right)\end{array}$} & \multirow{2}{*}{$\begin{array}{l}\text { Mean } \\
\text { reaction } \\
\text { distance } \\
(\mathrm{mm})^{*}\end{array}$} & \multirow[b]{2}{*}{$\begin{array}{c}\text { Mean zigzags } \\
\text { amplitude } \\
(\mathrm{mm})\end{array}$} & \multirow[b]{2}{*}{$\begin{array}{c}\text { Time on } \\
\text { particle (s) }\end{array}$} & \multicolumn{2}{|c|}{ Copepods speed $\left(\mathrm{mm} \mathrm{s}^{-1}\right)$} \\
\hline & & direct & chemical (lose) & & & & & & $\begin{array}{c}\text { before } \\
\text { encoutering } \\
\text { the trail }\end{array}$ & $\begin{array}{c}\text { following the } \\
\text { trail* }\end{array}$ \\
\hline \multirow[t]{3}{*}{ culture } & 127 & 50 & 77 (37) & $3.5( \pm 0.8)$ & 129 & $12.7( \pm 8.3)$ & 0.78 & $11.0( \pm 22.3)$ & $4.1( \pm 1.8)$ & $7.5( \pm 1.4)$ \\
\hline & 35 & 13 & $22(9)$ & $2.4( \pm 0.3)$ & 132 & $12.3( \pm 9.8)$ & 0.62 & $12.9( \pm 17.4)$ & $4.4( \pm 1.9)$ & $8.0( \pm 2.3)$ \\
\hline & 162 & 63 & $99(46)$ & $3.3( \pm 0.9)$ & 130 & $12.6( \pm 8.7)$ & 0.75 & $11.3( \pm 21.6)$ & $4.2( \pm 1.8)$ & $7.6( \pm 1.6)$ \\
\hline \multirow[t]{2}{*}{ wild } & 33 & 13 & $20(12)$ & $3.5( \pm 0.4)$ & 48 & $7.9( \pm 5.6)$ & 0.56 & $23.2( \pm 16.6)$ & $3.6( \pm 1.4)$ & $6.3( \pm 1.2)$ \\
\hline & 37 & 10 & $27(16)$ & $2.8( \pm 0.5)$ & 57 & $8.6( \pm 6.6)$ & 0.62 & $27.7( \pm 26.7)$ & $3.5( \pm 1.5)$ & $6.5( \pm 1.6)$ \\
\hline total & 70 & 23 & $47(28)$ & $3.1( \pm 0.6)$ & 54 & $8.3( \pm 6.2)$ & 0.60 & $26.1( \pm 23.7)$ & $3.5( \pm 1.5)$ & $6.5( \pm 1.5)$ \\
\hline
\end{tabular}


473 Figure 1 : (A) Relative position of Temora longicornis when it reacts to the chemical trail left 474 by sinking discarded house (represented here as a large dot). The two inserted images 475 represent the theoretical chemical plume assuming two different Péclet numbers (adapted 476 from Kiørboe et al. 2001). (B) Example of T. longicornis swimming pattern and speed (mm s-

$47{ }^{1}$ ) relative to position of sinking discarded houses. The detection point is marked with a black 478 arrow. Note the increased speed and the zigzagging behavior when following the chemical 479 trail.

480

481 Figure 2 : Frequency distribution of detection distance of $T$. longicornis to the sinking 482 aggregates. Wild and culture conditions were plotted separately since they were tested as 483 significantly different $\left(\chi^{2}\right.$-test $\left.p>0.05\right)$.

484

485

Figure $3: T$. longicornis fecal pellet production when offered discarded house at different concentrations (number $\mathrm{L}^{-1}$ ). Error bars represent the standard error originating from triplicates. Relationship is: $\mathrm{Y}=33.8( \pm 13.0) \mathrm{X} /(\mathrm{X}+133( \pm 73))\left(R^{2}=0.84 ; n=27\right)$ dotted lines represent the $95 \%$ confidence limits intervals of this relationship. 


\section{Figures}
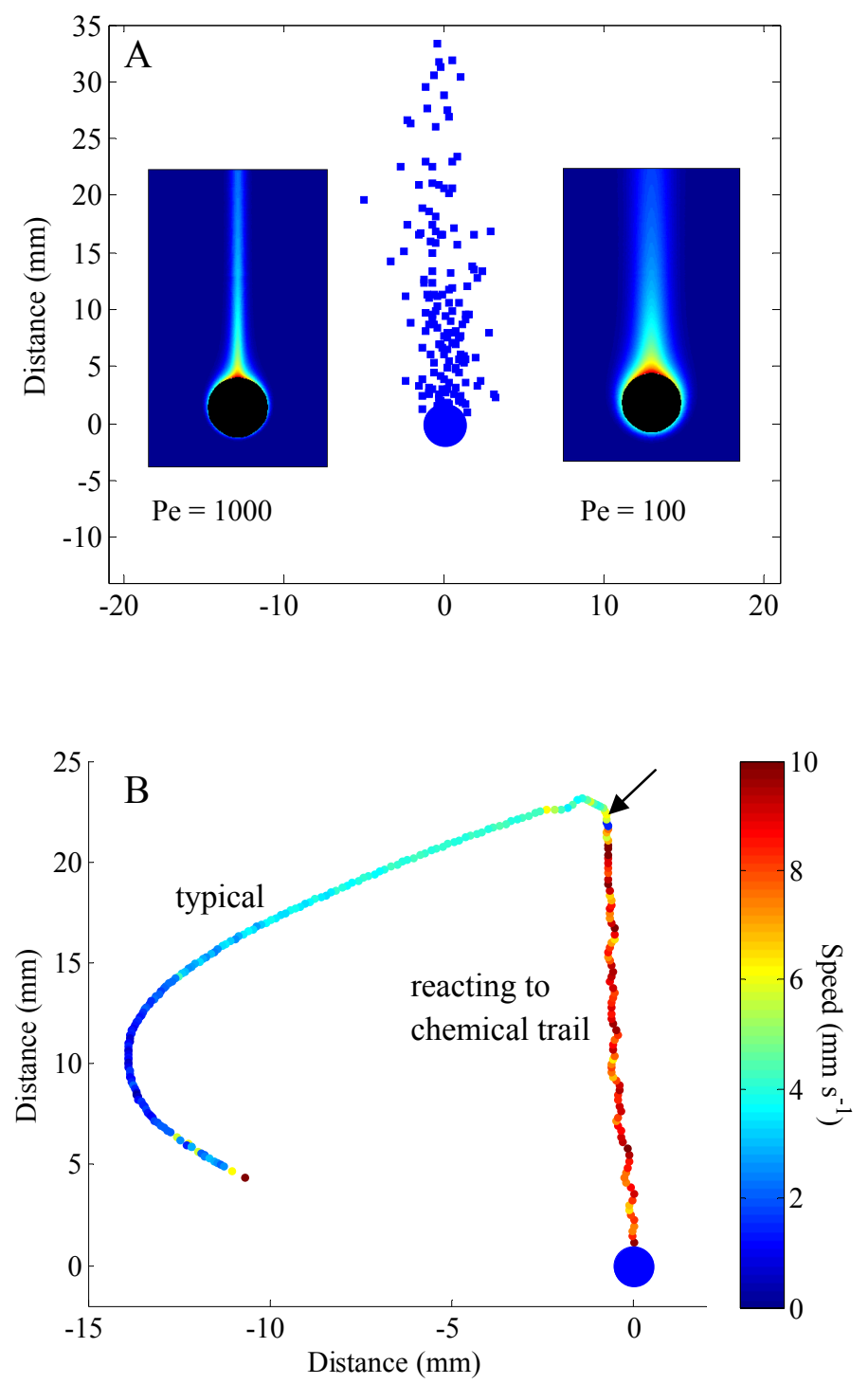

Figure 1 


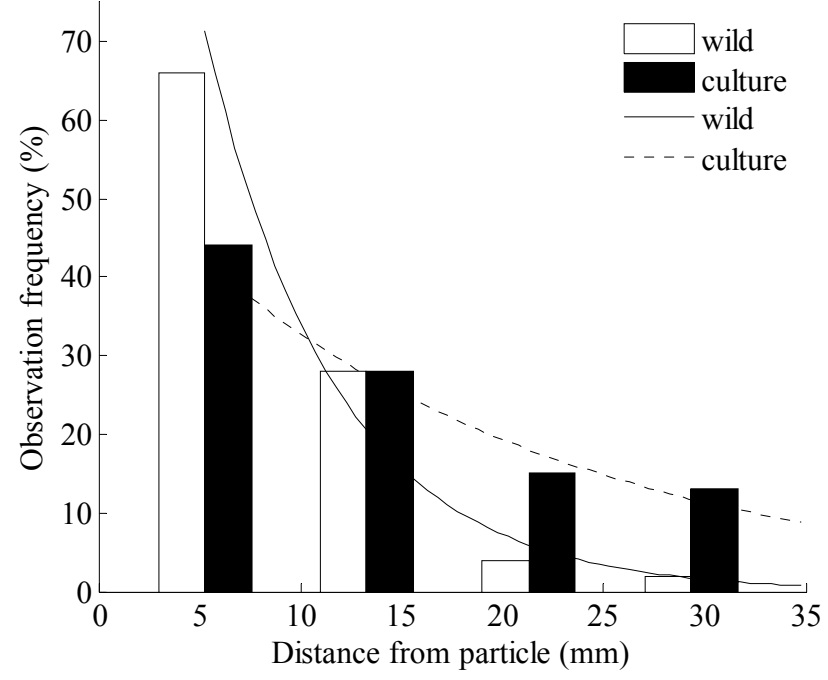

Figure 2 


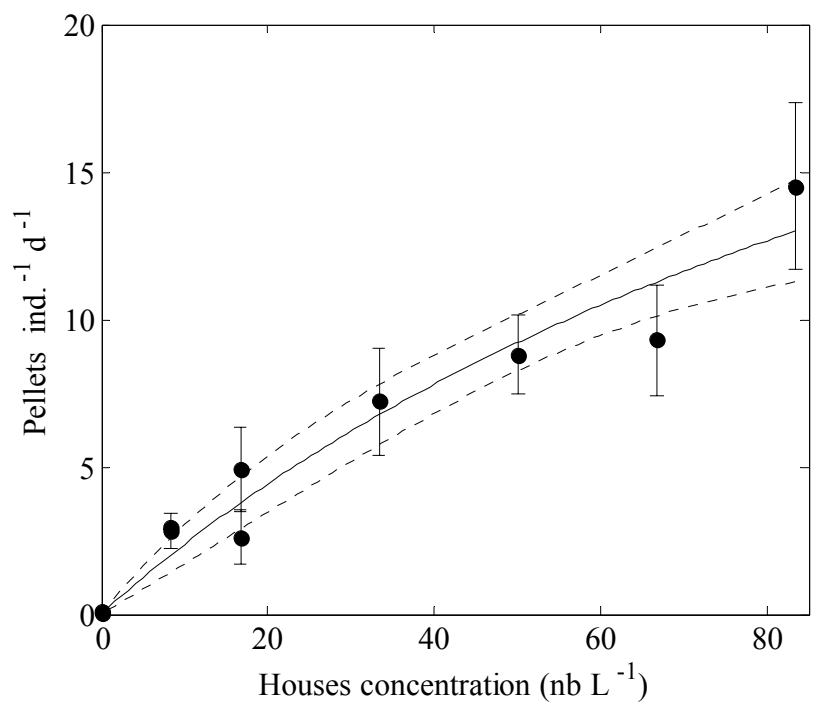

Figure 3 


\section{Web appendix}

These three video sequences illustrate the different behavioral observations described in the accompanying manuscript.

Video A1: Example of Temora longicornis interacting with sinking marine snow (discarded appendicularian house) using infra red light. All the different behavior (chemical trail detection, direct encounter) are illustrated.

Available online at:

http://fabien.lombard1.free.fr/temoratrackIR2.wmv

Video A2: Example of T. longicornis following a chemical trail left by a sinking marine snow (discarded appendicularian house) using white light illumination inside a rotating tank: http://fabien.lombard1.free.fr/temoratrackwhiteligth.wmv

Video A3: Close-up view of the feeding behavior of T. longicornis on marine snow (discarded appendicularian houses) using a binocular lens (inside a petri dish).

Available online at

http://fabien.lombard1.free.fr/closeupfeeding.wmv 